\title{
OCEAN DISPOSAL OF WASTEWATER
}




\section{ADVANCED SERIES ON OCEAN ENGINEERING}

Series Editor-in-Chief

Philip L- F Liu (Comell University)

Vol. 1 The Applied Dynamics of Ocean Surface Waves by Chiang C Mei (MIT)

Vol. 2 Water Wave Mechanics for Engineers and Scientists by Robert $G$ Dean (Univ. Florida) and Robert A Dalrymple (Univ. Delaware)

Vol. 3 Mechanics of Coastal Sediment Transport by Jørgen Fredsøe and Rolf Deigaard (Tech. Univ. Denmark)

Vol. 4 Coastal Bottom Boundary Layers and Sediment Transport by Peter Nielsen (Univ. Queensland)

Vol. 5 Numerical Modeling of Ocean Dynamics by Zygmunt Kowalik (Univ. Alaska) and TS Murty (Inst. Ocean Science, BC)

Vol. 6 Kalman Filter Method in the Analysis of Vibrations Due to Water Waves by Piotr Wilde and Andrzej Kozakiewicz (Inst. Hydroengineering, Polish Academy of Sciences)

Vol. 7 Physical Models and Laboratory Techniques in Coastal Engineering by Steven A. Hughes (Coastal Engineering Research Center, USA)

Vol. 8 Ocean Disposal of Wastewater by lan $R$ Wood (Univ. Cantertury), Robert $G$ Bell (National Institute of Water \& Atmospheric Research, New Zealand) and David L Wilkinson (Univ. New South Wales)

Forthcoming titles:

Water Waves Propagation Over Uneven Bottoms by Maarten W Dingemans (Delft Hydraulics)

Tsunami Run-up

by Philip L-F Liu (Cornell Univ.), Costas Synolakis (Univ. Southern Califomia), Harry Yeh (Univ. Washington) and Nobu Shuto (Tohoku Univ.)

Beach Nourishment: Theory and Practice by Robert $G$ Dean (Univ. Florida)

Design and Construction of Maritime Structures for Protection Against Waves by Miguel A Losada (Univ. da Cantabria) and Nobuhisa Kobayashi (Univ. Delaware) 


\title{
Advanced Series on Ocean Engineering - Volume 8
}

\section{OCEAN DISPOSAL OF WASTEWATER}

\author{
I. R. Wood \\ Civil Engineering Department \\ University of Canterbury \\ Christchurch, New Zealand \\ R. G. Bell \\ NIWA Ecosystems \\ National Institute of Water and Atmospheric Research \\ Hamilton, New Zealand \\ D. L. Wilkinson \\ Water Research Laboratory \\ University of New South Wales \\ Sydney, Australia
}




\author{
Published by \\ World Scientific Publishing Co. Pte. Ltd. \\ P O Box 128, Farrer Road, Singapore 9128 \\ USA office: Suite 1B, 1060 Main Street, River Edge, NJ 07661 \\ UK office: 73 Lynton Mead, Totteridge, London N20 8DH
}

\title{
OCEAN DISPOSAL OF WASTEWATER
}

Copyright 1993 by World Scientific Publishing Co. Pte. Ltd.

All rights reserved. This book, or parts thereof, may not be reproduced in any form or by any means, electronic or mechanical, including photocopying. recording or any information storage and retrieval system now known or to be invented, without written permission from the Publisher.

For photocopying of material in this volume, please pay a copying fee through the Copyright Clearance Center, Inc., 27 Congress Street, Salem, MA 01970, USA.

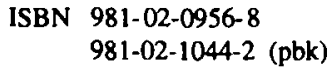

Printed in Singapore by JBW Printers \& Binders Pte. Ltd. 


\section{Preface}

This book has grown out of a series of lectures on the behaviour of outfalls that the senior author has given as part of the coastal engineering course at the University of Canterbury and a course on outfall design given at Cornell University while on leave in 1990. Since the classic book on outfalls by R. Grace (1978) and an outfall handbook by Williams (1985) there has been a great outpouring of papers on the fluid mechanics of outfall design. This book concentrates on the means of calculating mixing at an outfall and the quality of water near the shoreline and presents the authors' views of the state of the art and the research needs in this area in 1992. Research in this area is continuing and the recent development of sophisticated instrumentation promises to lead to an increase in our understanding of the sewage plume dilution. An example of one of the latest techniques, shown in the frontispiece, is laser-induced fluorescence.

The first chapter deals with the controversy over the ocean disposal of waste water. It is pointed out that the oceans have for all time been the ultimate sink for waste from pastures and rivers and provided that there is appropriate treatment and good trade waste collection facilities exist ocean disposal of waste is a viable option.

The next two chapters deal very briefly with the desired standard for water quality in the ocean and treatment options for the raw sewage before the ocean disposal.

With outfalls the initial dilution comes from the entrainment as the effluent rises to the surface and subsequent dilution and the decay of the pollution comes from the natural processes in the ocean. Chapters four to fourteen deal with initial dilution and chapters fifteen to seventeen deal with the ocean processes.

Chapters four and five outline the theory of the rising axisymmetric and merging plumes in a stationary environment. Although Chapter six presents the theory for a standard diffuser much more work still needs to be done in this area and it is suggested that chapter four presents an appropriate design theory. 
Chapter seven deals with interaction of the rising plume with the surface and the creation of the surface density field while chapter eight describes the rising plume in a stratified fluid. The methods used in the design of a diffuser in still water are presented in chapters nine and ten.

Chapters eleven to thirteen deal with a single plume in a current. Chapter eleven investigates a single port in a flow. It is pointed out that the flow is not simple but the velocity distribution goes from the Gaussian, typical of the plume where there is no current to a vortex distribution. The standard diffuser with horizontal ports sometimes gets attached to the bottom of the sea bed and the next chapter deals with the phenomena. The standard diffuser also consists of a number of ports and in a flow the plumes from these will merge. This makes a difference to the trajectory and the dilution of the effluent. This is discussed in chapter thirteen and there is a lot of work to be done in this area.

The siting of the outfall with respect to the shore and the ocean currents is vital and chapter fifteen describes the oceanographic investigations. For a surface field where the effluent is exposed to sunlight the bacteria decays and this is described in chapter sixteen. Chapter seventeen outlines the combination of the above to model the effects of the change of effluent from its initial dilution to the coastline.

The specialised problems of tunnels are described in chapter eighteen while chapters nineteen and twenty deal with the problems of outfall monitoring and construction.

Chapters one to fourteen, nineteen and twenty were written by I R Wood, chapters fifteen to seventeen by $\mathbf{R}$ Bell and I $\mathbf{R}$ Wood, while chapter eighteen was written by D L Wilkinson. Copies of the computer programs, (written in FORTRAN) which deal with the design of the diffuser, analysis of a single or merged plumes with a still fluid in uniform or linearly stratified density and for a single plume in a current are available by sending a $3 \frac{1}{2}$ inch IBM formatted disk to the senior author. 


\section{Acknowledgements}

A first draft of the book was prepared while the senior author was the Mary Upson Distinguished Visiting Professor at the School of Civil and Environmental Engineering, Cornell University. I would thank the University of Canterbury for granting sabbatical leave and my hosts at Cornell for their gracious hospitality and generous support.

I would express my appreciation for the discussions and the research contributions of my colleagues. The insights gained from communications with Gary McDonald, Gerhard Jirka, Kesayoshi Hadano, Brian Williams, Steven Wright and Joseph Hun-wei Lee were particularly valuable. My past students, Ian Brown, Merete Knudsen, Mark Davidson and Cheng Chi Wai have all contributed to some of the ideas developed in the book.

Chapters 15 to 17 were reviewed by G.B. McBride, R.J. Davies-Colley, S. Dumnov (all of WQC-NIWAR), A. Donnison (MIRINZ-Hamilton) and D. Munro (WRc-UK).

Finally, thanks are due Mrs V.J. Grey for producing the diagrams and Mrs A. Roberts who patiently typed the manuscript. 
This page is intentionally left blank

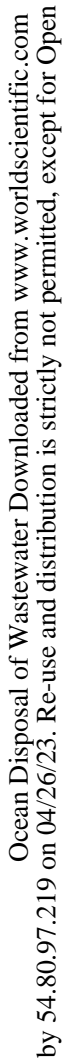




\section{Table of Contents}

1 Ocean Disposal of Wastewater $\ldots \ldots \ldots \ldots \ldots \ldots \ldots$

1.1 Introduction $\ldots \ldots \ldots \ldots \ldots \ldots \ldots \ldots$

2 The Standards for Water Quality and the Legislation For These

Standards ......................... 9

2.1 Introduction $\ldots \ldots \ldots \ldots \ldots \ldots \ldots \ldots \ldots \ldots \ldots$

2.2 Bacterial Standards For Water in Regions Where Shellfish Are Collected . . . . . . . . . . . . . . . 10

2.3 The Bacterial Standards For Bathing And Water Contact Sports ..................... 11

2.4 The Protection of Marine Life And Aesthetic Standards ....................... 14

2.5 The Means Of Achieving These Standards $\ldots \ldots \ldots \ldots 15$

3 The Quality of Untreated and Treated Effluent . . . . . . . 20

3.1 Introduction . . . . . . . . . . . . . . . . . . . 20

3.2 The Untreated Effluent $\ldots \ldots \ldots \ldots \ldots \ldots$

4 The Behaviour of a Buoyant Jet in a Stationary Uniform Environment ......................... 25

4.1 Introduction . . . . . . . . . . . . . . . . 25

4.2 The Pure Axisymmetric Jet ............. 26

4.3 The Axisymmetric Vertical Plume ............. 27

4.4 The Buoyant Plume Ejected at an Angle to the Vertical . 29

4.5 The Implications of the Spread Assumption . . . . . . 45

5 The Behaviour of a Merging Array of Buoyant Jets in a Stationary Uniform Environment . . . . . . . . . . . 48

5.1 Introduction . . . . . . . . . . . . . . . . 48

5.2 The Velocity Buoyancy Distributions . . . . . . . . 48

5.3 The Spread Equation ................ 53

5.4 The Equations for a Single Jet Within the Plane of Symmetry .................... 56

5.5 The Zone of Flow Establishment (The Initial Zone) . . . 57

5.6 A Comparison of the Theory and Experiments ......6 63 
6 The Dilutions from a Standard Diffuser . . . . . . . . . 71

6.1 Introduction . . . . . . . . . . . . . . . 71

6.2 The Calculations in the Region Below the Point at Which the Two Two-dimensional Buoyant Jets Merge . . . . . . 74

6.3 The Calculations for the Region Above the Point at Which the Two Two-dimensional Buoyant Jets Merge . . 77

6.4 The Numerical Procedure . . . . . . . . . . . . . . . . . 81

6.5 The Results of Dilution Calculations ........... 82

7 The Creation of the Effluent Field at the Ocean Surface ... . 85

7.1 Introduction . . . . . . . . . . . . . 85

7.2 The Two-dimensional Surface Plume ... . . . . . . . 85

7.3 The Axisymmetric Surface Plume . . . . . . . . . . 90

7.4 The Finite Length Diffuser . . . . . . . . . . 92

8 The Behaviour of Single and Merging Buoyant Jets in a Stratified Ocean $\ldots \ldots \ldots \ldots \ldots \ldots \ldots$

8.1 Introduction $\ldots \ldots \ldots \ldots \ldots \ldots \ldots \ldots$

8.2 The Horizontally Spreading Region $\ldots \ldots \ldots \ldots \ldots 106$

8.3 The Flow Below the Equilibrium Region . . . . . . . . . 106

8.4 The Flow Above the Equilibrium Region $\ldots \ldots \ldots \ldots 11$

8.5 The Computed Results . . . . . . . . . . . . . 112

9 The Preliminary Design for the Initial Dilution in a Stationary

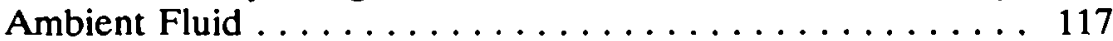

9.1 The Pipe Diameter . . . . . . . . . . . . . 117

9.2 The Port Diameters .................. 125

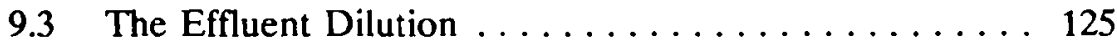

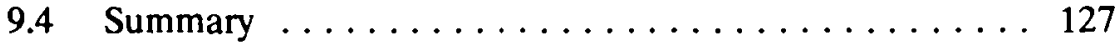

10 The Detailed Diffuser Design ... . . . . . . . . . . . . . . 129

10.1 Introduction . . . . . . . . . . . . . . . . . . . . . 129

10.2 Computer Solution .................. 132

10.3 Manual Solution . . . . . . . . . . . . . . . . 135 
11 The Effect of Currents on the Initial Dilution of a Buoyant Jet Rising in an Unstratified Fluid . . . . . . . . . . . . . 137

11.1 Introduction ......................... 137

11.2 The General Equations For a Flow With Gaussian Distributions of Velocity and Buoyancy ........... 142

11.3 The General Equations For the Flow With Vortex Like Distributions ..................... 154

11.4 Discussion of the Limiting Cases . . . . . . . . . . 164

11.5 The Condition For the Transition Between the Gaussian and Vortex Like Flows ................. 166

11.6 The Matching of the Flows at the Transition Section ... 172

11.7 The Conditions at the End of the Zone of Flow Establishment ....................... 173

11.8 Conclusion $\ldots \ldots \ldots \ldots \ldots \ldots \ldots \ldots \ldots \ldots \ldots$

12 The Effects of a Moving Stratified Fluid on Initial Dilution of a Single Buoyant Jet $\ldots \ldots \ldots \ldots \ldots \ldots \ldots \ldots \ldots \ldots$

12.1 Introduction $\ldots \ldots \ldots \ldots \ldots \ldots \ldots \ldots \ldots \ldots \ldots$

12.2 The Numerical Model Equation . . . . . . . . . . . . 191

13 Ground Effects and the Effect of a Current on the Instability of Single Buoyant Plumes . . . . . . . . . . . . . . . . . . . 197

13.1 Introduction . . . . . . . . . . . . . . . . . 197

13.2 The Flow Regime Classification . . . . . . . . . . 199

14 The Effects of Currents on the Final Submerged or Surface Field ............................... 204

14.1 Introduction ..................... 204

14.2 Deep Diffuser in Which Jets are Merged for a Large Part of Their Depth and the Rising Effluent Behaves as a Two-dimensional Plume (Brooks 1979) . . . . . . . . 204

14.3 The Dimensional Analysis Approach for a Deep Diffuser ......................... 206

14.4 The Experiments With Merging Plumes ........ 209

14.5 Experiment With Merging Plume in a Stratified Environment 
15 Oceanographic Investigations for Outfalls . . . . . . . . . 234

15.1 Introduction . . . . . . . . . . . . . . . . . . 234

15.2 Setting up an Oceanographic Study . . . . . . . . . 234

15.3 Eulerian Current Measurements . . . . . . . . . . . 238

15.4 Lagrangian Current Measurements ... . . . . . . . 250

15.5 Effluent Field Diffusion Measurements . . . . . . . 255

16 Inactivation of Faecal Indicator Bacteria $\ldots \ldots \ldots \ldots$

16.1 Introduction . . . . . . . . . . . . . . . . 266

16.2 Pathogens and Indicator Concepts $\ldots \ldots \ldots \ldots \ldots . \ldots 266$

16.3 Faecal Indicator Bacteria . . . . . . . . . . . . 269

16.4 Inactivation of Indicator Bacteria $\ldots \ldots \ldots 273$

17 Numerical Modelling of Wastewater Plume Advection,

Dispersion and Decay . . . . . . . . . . . . . . . 284

17.1 Introduction . . . . . . . . . . . . . . . . . . 284

17.2 Oceanographic Data Requirements . . . . . . . . . . 284

17.3 Approaches to Advection-Diffusion Modelling ....... 286

17.4 A Current Field Which Does Not Vary With Position or Time ....................... 288

17.5 A Current Field Which is Spatially Constant but Varies with Time According to a Current Meter Record .... 297

17.6 A Current Field Which Varies Temporally and Spatially According to a Computations Model . . . . . . . . . 302

18 Tunnelled Ocean Outfalls ................. 316

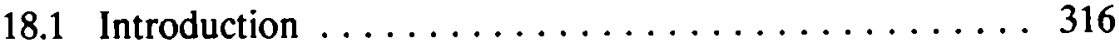

18.2 Physics of Outfall Purging . . . . . . . . . . . 318

18.3 Development of a Purging Criterion . . . . . . . . 322

18.4 Effluent Flow in Outfall Tunnel . . . . . . . . . . . . 327

18.5 Seawater Intrusion $\ldots \ldots \ldots \ldots \ldots \ldots \ldots \ldots \ldots \ldots$

18.6 Hydraulic Modelling of the Tunnel Riser Combination . 333

18.7 Modelling for Plume Dilution . . . . . . . . . . . 340

18.8 Recommendations for Design . . . . . . . . . . . 343 
19 Outfall Monitoring . . . . . . . . . . . . . . . 348

19.1 Introduction . . . . . . . . . . . . . . . . . 348

19.2 The Hastings Outfall Monitoring Programme . . . . . . . . 349

19.3 The Sydney Outfalls Monitoring Programme ... . . . . 352

19.4 Conclusion . . . . . . . . . . . . . . . . 356

19.5 The Hydraulic Performance of the Outfall Diffuser . . . . 357

20 Outfall Construction . . . . . . . . . . . . . . . 360

20.1 Introduction . . . . . . . . . . . . . . 360

20.2 The Outfall Pipe Foundations . . . . . . . . . 360

20.3 The Forces on the Outfall Pipe and its Foundations . . . . . 361

20.4 Outfall Pipe Material and the Methods of Construction . . . 370

Appendix 1 The Most Probable Number . . . . . . . . . . 376

Appendix 2 The Toxicity Unit . . . . . . . . . . . . . 377

Appendix 3 The Calculation of the Density of Fresh and

Salt Water .................... 378

Appendix 4 The Behaviour of a Buoyant Fluid Ejected at an

Arbitrary Angle to the Flow . . . . . . . . . . . 379

References ........................ 386

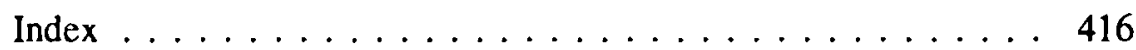




\section{List of Figures}

Figure 1.1 The ocean outfall in an unstratified ocean where $b_{d}$ is the diffuser length, $2 p_{s}$ is the port spacing on one side of the diffuser, $z_{\mathrm{s}}$ is the depth to the free surface, $z_{\mathrm{b}}$ is the depth to the base of the effluent field, $z_{u}$ is the depth of the surface effluent field, $U_{\infty}$ is the velocity of the ambient fluid and $\rho_{\mathrm{a}}$ is the density of the ambient fluid.

Figure 1.2 The tunnelled outfall.

Figure 1.3 The outfall plume in a stratified ocean current.

Figure 2.1 The dependence of highly credible gastrointestinal symptoms on enterococci coliforms [Cabelli (1989)].

Figure 2.2 The distribution of coliform counts determined from a large number of samples at a U.K. beach for the 1965 and 1966 seasons (Moore 1975).

Figure 3.1 Variations of daily sewage flow rates for a typical residential area (Williams 1985).

Figure 4.1 $\mathrm{A}$ jet like flow. In this figure $\overline{\mathrm{u}}$ is the time averaged velocity, $U$ is the time averaged centreline velocity and $\mathrm{U}_{\alpha}$ is the entrainment velocity in the outer field. At any instant the velocity $\overline{\mathrm{u}}$ is made up of the time averaged velocity $u$ and its fluctuation $u^{\prime}$.

Figure 4.2 The dimensionless mean velocity profile (Papanicolaou, 1984).

Figure 4.3 The dimensionless mean concentration profile (Papanicolaou, 1984).

Figure 4.4 The dimensionless mean turbulent fluctuation profile in a plume (Papanicolaou, 1984). 
Figure 4.5 The dimensionless profile of the flux of concentration due to the turbulent fluctuations. Integrating this curve shows that approximately 20 percent of the concentration flux is due to the turbulent fluctuations. (Papanicolaou, 1984).

Figure 4.6 The plume ejected horizontally into a still fluid.

Figure 4.7 The profiles of $p / \rho \bar{U}^{2}$ and $\bar{u}^{2} / \bar{U}^{2}$ as a function of $\eta$. In this two dimensional flow $u / U=\exp \left(-\eta^{2}\right)$ where $\eta=\mathrm{x} / \mathrm{b}$ and $\mathrm{x}$ is measured from the jet centreline. [Bradbury (1965)].

Figure 4.8 A plot of Papanicolaou's momentum data for a buoyant jet. The value of $M$. was calculated from the value of $I_{m}$ and the measured values of $b$. and $U$.

Figure 4.9 A plot of Papanicolaou's dilution with the numerical computation. Papanicolaou's dilution data was computed from the value of the shape function $I_{q \Delta}$ and the measured values of $b$. and $U$.

Figure 4.10 A comparison of dilution measurements with the numerical model and Cederwall's empirical formulae. This plot is of the form used by Roberts 1977 . S is $\Delta_{\mathrm{o}} / \Delta$ and is the centreline dilution.

Figure 4.11 A comparison of trajectories calculated from the numerical model with measured trajectories (Davidson 1988). The initial momentum has been calculated using the momentum correction coefficient for laminar flow (Streeter and Wylie 1979).

Figure 4.12 A comparison of the trajectories calculated from the numerical model with the measured trajectories. In this case the flow is turbulent and the momentum correction coefficient is taken as 1.0 (Davidson 1988). 
Figure 4.13 A comparison of the computed trajectories with the experimental results published in Anwar (1969).

Figure 5.1 The merging of axisymmetric buoyant plumes (after Davidson 1989).

Figure 5.2 Nomenclature for the single buoyant jet between the planes of symmetry (after Davidson 1989).

Figure 5.3 The assumed velocity profile for the merging buoyant plumes. For the buoyancy profile $b_{p}$ is replaced with $\lambda b_{p}$.

Figure 5.4 The shape constants and spread function ( $\lambda$ varying).

Figure 5.5 The initial zone length.

Figure 5.6 The angle of the buoyant jet at the end of the initial zone.

Figure 5.7 The initial conditions for a buoyant jet ejected horizontally into a stationary fluid.

Figure 5.8 The empirical modification for the case where the jet is at angle $\theta_{p}$ to the horizontal.

Figure 5.9 A comparison of merged vertical buoyant jet results with the two-dimensional slot jet solution. The experimental results come from Kotsovinos (1975).

Figure 5.10 A comparison of Cederwall's trajectory and dilution data with the computed curves.

Figure 5.11 A comparison of Knystautas' velocity data with the computed curves.

Figure 5.12 The trajectories for a horizontal buoyant jet with a Froude Number of 20 with ratios of port spacing to diameter of 5,10 and 100 . 
Figure 4.13 A comparison of the computed trajectories with the experimental results published in Anwar (1969).

Figure 5.1 The merging of axisymmetric buoyant plumes (after Davidson 1989).

Figure 5.2 Nomenclature for the single buoyant jet between the planes of symmetry (after Davidson 1989).

Figure 5.3 The assumed velocity profile for the merging buoyant plumes. For the buoyancy profile $b_{p}$ is replaced with $\lambda b_{p}$.

Figure 5.4 The shape constants and spread function ( $\lambda$ varying).

Figure 5.5 The initial zone length.

Figure 5.6 The angle of the buoyant jet at the end of the initial zone.

Figure 5.7 The initial conditions for a buoyant jet ejected horizontally into a stationary fluid.

Figure 5.8 The empirical modification for the case where the jet is at angle $\theta_{p}$ to the horizontal.

Figure 5.9 A comparison of merged vertical buoyant jet results with the two-dimensional slot jet solution. The experimental results come from Kotsovinos (1975).

Figure 5.10 A comparison of Cederwall's trajectory and dilution data with the computed curves.

Figure 5.11 A comparison of Knystautas' velocity data with the computed curves.

Figure 5.12 The (a) trajectories and (b) dilutions for a horizontal buoyant jet with a Froude Number of 20 with ratios of port spacing to diameter of 5,10 and 100 . 
Figure 5.13 Generalised curves for the dilution of merging buoyant jets.

Figure 5.14 The difference between an axisymmetric and a twodimensional buoyant jet. Note the prominent instabilities in the two-dimensional buoyant plume.

Figure 6.1 The merging diffuser plumes (schematic).

Figure 6.2 The velocity distribution in (a) the merging portion of jets from a diffuser and (b) the buoyant jet in a coflow.

Figure 6.3 The merging plume geometry for the case when $\left(p_{s} / b\right)_{m}=3.4$.

Figure 6.4 The velocity distribution approximation.

Figure 6.5 The solution domain.

Figure 6.6 The computed dilutions.

Figure 6.7 A comparison of the computed and measured dilutions. (The measured results are from Liseth 1970.)

Figure 7.1 A possible two-dimensional flow (a) The natural solution and (b) the experiments of Didden and Maxworthy, (1982) and Britter, (1979).

Figure 7.2 A comparison of the two-dimensional experiments of Didden and Maxworthy (1982) and Britter (1979).

Figure 7.3 The advance of a density current over a horizontal bed (Wilkinson 1970).

Figure 7.4 The two-dimensional plume entering an established effluent field. 
Figure 7.5 The flow from a finite length diffuser in a stationary ocean (schematic). The $\psi$ value is the stream function, $b_{p}$ is the diffuser width and the lines of constant $\psi$ are streamlines.

Figure 7.6 The axisymmetric plume experiment.

Figure 7.7 The axisymmetric plume experiment. Note that with the greater depth $\mathrm{qr}_{\mathrm{r}}$ is larger and for a particular $\mathrm{t}, \mathrm{r}$ is greater than in Figure 7.6. This is consistent with the results in Table 7.2.

Figure 7.8 The solution of equation 7.13. Note the coincidence of the solution and $\mathrm{F}_{\mathrm{u}}^{2}+\mathrm{F}_{\mathrm{q}}^{2}-1=0$.

$\left[\mathrm{F}_{\mathrm{u}}^{2}=\mathrm{q}_{\mathrm{u}}^{2} / \Delta \mathrm{z}_{\mathrm{u}}^{3}\right.$ and $\left.\mathrm{F}_{\mathrm{l}}^{2}=\mathrm{q}_{\mathrm{e}}^{2} / \Delta\left(\mathrm{z}_{\mathrm{s}}-\mathrm{z}_{\mathrm{u}}\right)^{3}\right]$.

Figure 7.9 The axisymmetric plume experiments, Wright et al. (1991).

Figure 8.1 Outlines of a plume rising in a stratified environment $\mathrm{Fr}_{\mathrm{o}}=7.1$ (after Abraham and Eysink (1989)).

Figure 8.2 The density distribution on the plume centreline. $z_{0}$ is the bottom level of the spreading layer (after Abraham and Eysink (1969)).

Figure 8.3 The density difference distribution in a vertical plume $\left(\mathrm{z}_{\mathrm{m}}\right.$ is the maximum plume height, $\mathrm{z}_{\mathrm{T}}$ is the top of the spreading layer, $\mathrm{z}_{\mathrm{e}}$ is the height to the minimum dilution in the spreading layer and $z_{0}$ is the bottom of the spreading layer). Note the density deficit distribution continues to spread even though the rising effluent is above the equilibrium level. The data is from Wong (1986).

Figure 8.4 The dimensionless maximum rise height of a vertical axisymmetric plume in a linearly stratified fluid. (The data is from Wong (1986) and Abraham and Eysink (1969).) 
Figure 8.5 The maximum dilution in the spreading layer from a vertical axisymmetric plume in a linearly stratified fluid. (The data is from Wong (1986).)

Figure 8.6 The dimensionless data for the height and the depth of the spreading layer from an axisymmetric plume in a linearly stratified fluid. (The data is from Wong (1986).)

Figure 8.7 The dimensionless maximum rise height and the height to the minimum dilution in the spreading from a twodimensional vertical rising plume. (The data is from Wallace and Wright (1979) and Wright and Wallace (1984).)

Figure 8.8 The minimum dilution in the spreading layer from a twodimensional buoyant jet in a linearly stratified fluid. (The data is from Wright and Wallace (1984).)

Figure 8.9 The concentrations in the spreading layer from a twodimensional vertical buoyant jet in a linearly stratified fluid. The flow is momentum dominated. $C_{m}$ is the maximum concentration and $\mathrm{C}$ is the locally measured concentration. (Wright and Wallace (1984).)

Figure 8.10 The concentrations in the spreading layer from a buoyancy dominated two-dimensional vertical buoyant jet in a linearly stratified fluid. The flow is buoyancy dominated. $\mathrm{C}_{\mathrm{m}}$ is the maximum concentration and $\mathrm{C}$ is a locally measured concentration. (Wright and Wallace (1984).)

Figure 8.11 The nomenclature for the buoyant jet in a stratified environment.

Figure 8.12 The breakdown of the spread or entrainment equation. 
Figure 8.13 The dimensionless rise height for an axisymmetric buoyant jet ejected horizontally into a stratified fluid. In the plume like region the difference between the computed and experimental height is approximately 20 percent (Wong 1986).

Figure 8.14 The dimensionless dilution for an axisymmetric buoyant jet ejected horizontally into a stratified fluid (Wong 1986).

Figure 8.15 The geometry of the spreading layer (Wong 1986).

Figure 9.1 The salt water intrusion.

Figure 9.2 Port Froude numbers and a nozzle at incipient intrusion for an orifice as a function of inclination to the horizontal. The port Froude number is defined as $U_{o} /\left(\Delta_{o} d_{p}\right)^{0.5}$ where $U_{o}$ is the nozzle velocity and $d_{p}$ is the diameter as illustrated in the figure (after Wilkinson 1988).

Figure 9.3 A comparison of the Ackers-White formulae for the critical velocity in a pipe with the experimental result for the $299 \mathrm{~mm}$ pipe $\left(\mathrm{d}_{\mathrm{s}}\right.$ is the depth of the sediment deposit and $\mathrm{D}$ is the pipe diameter).

Figure 9.4 The Timaru Outfall (courtesy of Beca Steven).

Figure 9.5 Typical Outfall and Outfall Risers.

(a) The Grimsby outfall diffuser (Brown, 1988).

(b) A riser on the Eastbourne outfall (NevilleJones and Proctor, 1988).

Figure 9.6 Chart for estimating minimum initial dilution for horizontal buoyant jet discharges (based on Cederwall's empirical relationship).

Figure 10.1 The flow from a single port. 
Figure 10.2 The Waitara outfall riser model. (Dimensions in mm, model scale 1:4.)

Figure 10.3 The head losses in a multiport diffuser.

Figure 11.1 A trace showing the variation of concentration in the outfall boil above one of the outfall ports at Waitara. The concentration of the effluent prior to the discharge was $750 \mathrm{mg} / \mathrm{m}^{3}$.

Figure 11.2 The jet in a coflow.

Figure 11.3 The advected thermal.

Figure 11.4 The advected thermal being approached by an advected Gaussian distribution (after Davidson 1989).

Figure 11.5 The momentum vortex being approached by a jet like flow.

Figure 11.6 The velocity components for flows where the effluent is ejected in the $\mathrm{z}$ direction. (The ambient flow is in the $\mathrm{x}$ direction.)

Figure 11.7 The nomenclature.

Figure 11.8 The control volume.

Figure 11.9 The advected buoyant plume trajectory data [Wright (1977a)] (The lengths are made dimensionless with $\ell_{\mathrm{P}, A}\left(\mathrm{q}_{\Delta \mathrm{O}} / \mathrm{U}_{\varpi}^{3}\right)$.)

Figure 11.10 The establishment of a line vortex pair in a buoyant jet issuing vertically into a crossflow.

Figure 11.11 The variation of the trajectory coefficient for the advected jet. 
Figure 11.12 The variation of the trajectory coefficient for an advected plume.

Figure 11.13 The variation of the dimensionless velocity $U_{e g} / U_{\infty}$ with a dimensionless distance $\mathrm{x} / \ell_{\mathrm{J}, \mathrm{wJ}}$. The data are from Landis and Shapiro (1951), Challen (1968), Antonia and Bilger (1974), Biringen (1975), Smith and Hughes (1977) and Knudsen (1988),

(where $\left.\ell_{J, W J}=\left(\pi \mathrm{d}_{\mathrm{p}}^{2} \mathrm{U}_{\mathrm{o}}\left(\mathrm{U}_{\mathrm{o}}-\mathrm{U}_{\mathrm{\omega}}\right) /\left(4 \mathrm{U}_{\mathrm{\omega}}^{2}\right)\right)^{0.5}\right)$.

Figure 11.14 The spread of the jet in a coflow. Both the width and the distance have been made dimensionless with $\left.\ell_{\mathrm{J}, \mathrm{wJ}}\left(\pi \mathrm{d}_{\mathrm{p}}^{2} \mathrm{U}_{\mathrm{o}}\left(\mathrm{U}_{\mathrm{o}}-\mathrm{U}_{\mathrm{o}}\right) /\left(4 \mathrm{U}_{\mathrm{\omega}}^{2}\right)\right)^{0.5}\right)$. The data are from Antonia and Bilger (1974), Biringen (1975), Smith and Hughes (1977) and Knudsen (1988).

Figure 11.15 The dilution of a tracer released into a jet in a coflow as a function of $x / \ell_{\mathrm{J}, \mathrm{WJ}}$ (where $\left.\ell_{\mathrm{J}, \mathrm{WJ}}=\left(\pi \mathrm{d}_{\mathrm{p}}^{2} \mathrm{U}_{\mathrm{o}}\left(\mathrm{U}_{\mathrm{o}}-\mathrm{U}_{\mathrm{o}}\right) /\left(4 \mathrm{U}_{\mathrm{o}}^{2}\right)\right)^{0.5}\right)$. The data are from Knudsen (1988).

Figure 11.16 The advected vortex flow.

Figure 11.17 The concentration contours in an advected line thermal (Fan 1967).

Figure 11.18 A concentration contour for a number of sections downstream from the source of an advected line thermal plotted in a non-dimensional form ( $\lambda \mathrm{b}$ is defined as the horizontal distance to the position where $c=c_{m} / e$ ).

Figure 11.19 The trajectories of an advected momentum vortex generated by a vertical jet where $\ell_{\mathrm{J}, \mathrm{MV}}=\left(\pi \mathrm{d}_{\mathrm{p}}^{2} \mathrm{U}_{\mathrm{o}}\left(\mathrm{U}_{\mathrm{o}}\right.\right.$ $\left.\left.\mathrm{U}_{\mathrm{\omega}}\right) /\left(4 \mathrm{U}_{\infty}^{2}\right)\right)^{0.5}$ (Chu 1985).

Figure 11.20 The growth of width of a momentum vortex generated by a vertical jet where $\ell_{\mathrm{J}, \mathrm{MV}}=\left(\pi \mathrm{d}_{\mathrm{p}}^{2} \mathrm{U}_{\mathrm{o}}\left(\mathrm{U}_{\mathrm{o}}-\mathrm{U}_{\mathrm{o}}\right) /\left(4 \mathrm{U}_{\mathrm{s}}^{2}\right)\right)^{0.5}$ (Knudsen 1989). 
Figure 11.21 The trajectories of the advected line thermal (where $\left.\ell_{P, A}=q_{\Delta o} / U_{*}^{3}\right)$.

Figure 11.22 The growth of width of the advected line thermal (where $\left.l_{P, A}=q_{\Delta o} / U_{\omega}^{3}\right)$. The measured width was from the concentration distribution and is thus $\lambda b$.

Figure 11.23 The trajectory coefficient for an advected line thermal as a function of $U_{*} / U_{\circ}$.

Figure 11.24 The trajectory coefficient for an advected momentum vortex as a function of $U_{*} / U_{o}$.

Figure 11.25 The correlation between the trajectory coefficients of the advected jet and the advected momentum vortex.

Figure 11.26 The dilution data of Wright (1977) and Fan (1967) (where $\ell_{P, A}=q_{\Delta O} / U_{*}^{3}$ ).

Figure 11.27 The prototype dilution data from Sidmouth, Gosport, Bridport and Hastings from Lee et al. (1987) (where $\left.\ell_{P, A}=q_{\Delta O} / U_{\bullet}^{3}\right)$.

Figure 11.28 The prototype dilution data from Hastings (1980) from Lee et al. (1987) (where $\ell_{P_{A}}=q_{\Delta o} / U_{*}^{3}$ ).

Figure 11.29 A plot of a dimensionless dilution as a function of $z / \ell_{P, A}$. Wright 1977 (where $\ell_{P, A}=q_{\Delta o} / U_{\omega}^{3}$ ).

Figure 11.30 A plot of a dimensionless dilution as a function $z / \ell_{P, A}$. Lee and Neville-Jones (1987) (where $\ell_{P, A}=q_{\Delta O} / U_{*}^{3}$ ).

Figure 11.31 The data from Wright (1977) for the transition from a jet to a momentum vortex $\left(\alpha_{\mathrm{r}}=\pi / 2\right)$.

Figure 11.32 The effect of a crossflow on the zone of flow establishment. 
Figure 11.33 The position of the flow angle at the end of the zone of flow establishment. I is the position of the end of the zone of flow establishment. The average direction of the flow in the zone of flow establishment is $\alpha_{\mathrm{rI}}+\delta / 2$.

Figure 11.34 A comparison of the computed output with the trajectory and dilution data of Fan (1967).

Figure 11.35 A comparison of the computed output with the trajectory and dilution data of Fan (1967).

Figure 11.36 A comparison of the computed output with the trajectory data and dilution data of Fan (1967).

Figure 11.37 A comparison of the computed output with the trajectory data of Chu and Goldberg (1974).

Figure 11.38 A comparison of the computed output with the trajectory data of Chu and Goldberg (1974).

Figure 11.39 A comparison of the computed output with the trajectory data of Davidson (1989).

Figure 11.40 A comparison of the computed output with the trajectory data of Davidson (1989).

Figure 11.41 A comparison of the computed output with the trajectory data of Knudsen (1988).

Figure 11.42 A comparison of the computed data with the trajectory of Davidson (1989).

Figure 11.43 The computed trajectories for a buoyant jet ejected horizontally and in the same direction as an ambient flow.

Figure 11.44 A comparison of computed and the measured dilutions (Lee and Neville-Jones 1987). 
Figure 12.1 The flow patterns for a buoyant jet rising through a flowing stratified fluid (not to scale).

Figure 12.2 The dimensionless equilibrium and maximum height, $\mathrm{M}_{\mathrm{co}}$, for a jet rising through a flowing stratified fluid. The flow is dominated by the initial jet momentum. (Replotted from Wright's 1977 data.)

Figure 12.3 The equilibrium and maximum heights for a buoyant plume rising through a flowing stratified fluid. The flow is dominated by the released buoyancy. The calculated line comes from the numerical model described in this chapter. It is for a densimetric Froude Number of 10 and a strong stratification $\left(5^{\circ} \mathrm{C}\right.$ over 10 metres). (Replotted from Wright's 1977 data.)

Figure 12.4 The intermittency function for a pure jet (after Hinze 1959).

Figure 13.1 The attachment mechanism - the pressure distribution on the surface is a result of entrainment demand and the increased velocity in the small area above the jet.

Figure 13.2 The instability of a buoyant jet with an approaching flow (a counterflow). In (a) the newest tracer is above the port, in (b) it is level with the port and in (c) it is below the port. The arrow marks the position of the port.

Figure 13.3 The buoyant jet in still ambient fluid.

Figure 13.4 The buoyant jet in a coflow. 202

Figure 13.5 (a-e) The buoyant jet in a counterflow. 202

Figure 13.6 Regime chart for buoyant jets in coflow, still ambient and counterflow. Some flume experiments were carried out where the port was stationary and there was an imposed current. For these experiments the values of $\mathrm{Fr}_{\mathrm{o}}\left(\mathrm{d}^{\prime} / \mathrm{d}_{\mathrm{p}}\right)$ were varied between 4 and 15 . 
Figure 14.1 A sketch of the flow pattern in the drowned jump.

Figure 14.2 The results for the flow perpendicular to the diffuser (after Roberts 1979).

Figure 14.3 The results for the flow parallel to the diffuser (after Roberts 1979).

Figure 14.4 The attachment of the effluent behind a two dimensional slot jet (after Roberts 1979).

Figure 14.5 The dilutions for a line plume in a crossflow from Roberts 1979.

Figure 14.6 Plan view of the experimental set up.

Figure 14.7 The range of flow patterns for merging buoyant jets in a crossflow (after Méndez-Díaz 1992).

Figure 14.8 The trajectories of merged buoyant jets in a coflow as a function of CF for a small ratio of port spacing to port diameter (replotted from the results of Méndez-Díaz, 1992).

Figure 14.9 The trajectories of merged buoyant jets in a coflow as a function of CF for a large ratio of port spacing to port diameter (replotted from the results of Méndez-Díaz, 1992).

Figure 14.10 A comparison of the trajectories of a single plume and the merged plumes. Note the lower horizontal surface of the merged plumes. The merging is in the advected thermal region and the value of $\mathrm{CF}$ was 33 (from Davidson 1989). 
Figure 14.11 Concentration measurements and dilutions measured in a single plume (the upper diagram) and in merged plumes (the lower diagram). Note that there is little difference between the dilutions. (From Davidson, 1989.)

Figure 14.12 A comparison of the trajectories of a single plume and the merged plumes. Note the jump on the lower surface of the merged plumes. The merging is in the advected plume region. (From Davidson 1989.)

Figure 14.13 A comparison of the trajectories of a single plume and the merged plume in a coflow. Note the jump; at the lower surface where the buoyant jets merge and the short length horizontal interface on the lower surface following the jump. The value of CF was 1.0. (From Davidson 1989.)

Figure 14.14 Concentration and dilution measurements on the centreline of a single plume and of merged plumes. The value of $C F$ was 1.5 . Note the irregularity of the concentration traces and the apparent breakup of the plume in the merged case. (From Davidson 1989.)

Figure 14.15 Trace of the outlines of an array of buoyant jets in a counterflow. Note the almost horizontal lower surfaces. (From Knudsen 1988.)

Figure 14.16 The dilutions measured on the centreline of a single plume.

Figure 14.17 The dilutions measured in the merged plumes. The value of $\mathrm{p}_{\mathrm{s}} / \mathrm{d}_{\mathrm{p}}$ was 18.18 .

Figure 14.18 The experimental arrangement. The case illustrated is where only the plume from the edge port (B) is dyed. Experiments were also carried out when only the plume from the central port (A) is dyed. 
Figure 14.19 The trajectories of the plume from the central port of an array of merging buoyant jets. The merging is in the advected thermal region. (From Cheng 1989.)

Figure 14.20 The trajectories of the central plume from an array of merging buoyant jets. The merging is in the advected plume region. (From Cheng 1989.)

Figure 14.21 A comparison of the trajectories of the plumes from the central and edge ports for the case where the merging is in the advected plume region. The section through the effluent field is schematic only. (From Cheng 1989.)

Figure 14.22 A comparison of the trajectories of the plume from the central and edge port for the case where the merging is in the advected thermal region. The cross-section through the effluent cloud is schematic only. (From Cheng 1989.)

Figure 14.23 The behaviour of an array of vortices.

Figure 14.24 A comparison of the trajectories of the plumes from the central and edge ports for the case where the merging is close to the advected plume - advected thermal transition. The sections through the effluent field is schematic only. (From Cheng 1989.)

Figure 14.25 The tee shape diffuser (Roberts et al., 1989).

Figure 14.26 The flow patterns for the buoyant jets rising from the diffuser illustrated in Figure 14.25. The diffuser is perpendicular to the flow and the ambient fluid is stratified (Roberts et al., 1979).

Figure 14.27 The flow patterns for the buoyant jets from the tee shaped diffuser illustrated in Figure 14.25. The diffuser is parallel to the flow and the ambient fluid is stratified (Roberts et al., 1989). 
Figure 14.28 The minimum dilutions in the equilibrium flow field for the flows from the tee shaped diffuser (Roberts et al. 1989).

Figure 14.29 The height of rise and thickness of the effluent field from the tee shaped diffuser. The diffuser is parallel to the flowing ambient fluid (Roberts et al. 1989).

Figure 14.30 The height of rise and thickness of the effluent field for the effluent field rising from the tee shaped diffuser. The diffuser is perpendicular to the flowing ambient fluid (Roberts et al. 1989).

Figure 14.31 The ratio of average to minimum dilution for the merged field from the tee shaped diffusers (Roberts et al., 1989).

Figure 15.1 Oceanographic investigations.

Figure 15.2 Methods of mooring recording current meters (RCM's) in shallow coastal waters (Bell et al., 1988).

Figure 15.3 An electromagnetic current meter: the InterOcean S4 meter has titanium electrodes and a solid-state memory.

Figure 15.4 Range and frequency distribution of average initial dilutions for a typical outfall using a 6 week RCM current record $(\Delta t=10 \mathrm{~min})$. (Note: Current speeds varied from $0.5-77 \mathrm{~cm} / \mathrm{s}$.)

Figure 15.5 Principal components of a current velocity time series. 
Figure 15.6 Current speed frequency distribution for Wanganui outfall site over 40 days. In this figure the median (50-percentile) current speed is relatively high at nearly $18 \mathrm{~cm} / \mathrm{s}$ for all directions, with 10 percent of all speeds being less than $4 \mathrm{~cm} / \mathrm{s}$ and 10 percent above $41 \mathrm{~cm} / \mathrm{s}$. $\mathrm{AB}$ is the percentage of time the currents are less than $18 \mathrm{~cm} / \mathrm{s}, \mathrm{AC}$ is the percentage of time the currents are less than $18 \mathrm{~cm} / \mathrm{s}$ and are in the $\mathrm{SE}$ direction and $\mathrm{CB}$ is the percentage of time the currents are less than $18 \mathrm{~cm} / \mathrm{s}$ and are in the NW direction.

Figure 15.7 Vector averaged velocities off the South Wellington coast are various RCM sites. These show the net current averaged over the deployment period ( $>4$ weeks) (Bell 1988).

Figure 15.8 Waitara embayment - outfall and current meter sites and nearshore segments (depths in $\mathrm{m}$ below Chart Datum) (Bell 1988).

Figure 15.9 Vector plot from two current meter records (sites $\mathrm{J}$ and D) off Waitara for the same 58 day period (Bell 1988).

Figure 15.10 A typical sail drogue and float assembly (Williams 1985).

Figure 15.11 Typical drogue tracks marked at hourly intervals from Moa Point (Wellington) outfall investigation from Beca Carter-Caldwell and Connell (1980).

Figure 15.12 Typical tracks of several dye patches released simultaneously for the Moa Point (Wellington) outfall investigation from Beca Carter-Caldwell Connell (1980).

Figure 15.13 The predicted percentage of time the effluent moves into Wellington Harbour during flood tides. This comes from the necessarily limited sample of drogue and dye tests. Beca Carter-Caldwell Connell (1980). 
Figure 15.14 The diffusion of a turbulent patch in homogeneous turbulence (Fischer et al, 1979).

Figure 15.15 Concentration profiles across a continuous plume at a fixed section downstream from the source (Csanady, 1973). The profiles are at the same section for repeated experiments. For a large number of runs the averaged profiles with the centres of mass superimposed are shown in Figure 15.16.

Figure 15.16 Profiles of average concentrations. The averaging was carried out by determining the centre of gravity of each profile trace (e.g. Figure 15.15) and making these coincident. The concentrations were then averaged in the normal manner. This profile is then a measure of the relative diffusion from the centre of gravity of the dye. The centre of gravity will also meander and thus the absolute diffusion will be greater than the relative diffusion (Csanady, 1973).

Figure 15.17 The variation of horizontal diffusivity $\left(\epsilon_{y}\right)$ in the ocean with the length scale (Okubo 1974). This diffusivity is calculated assuming the patch expands radially such that $\epsilon_{y}=\epsilon_{x}$. This is discussed further in Chapter 17.

Figure 15.18 Typical synoptic plan view of dye concentration contours and boat traverse (G Greentree - pers. comm.).

Figure 16.1 The concentrations of dye and coliforms in the centre of sewage field relative to initial concentrations in the boil above - (Ventura Outfall, U.S.A.). This figure shows the relative magnitude between physical dilution and bacterial inactivation during daylight. (After Foxworthy and Kneeling, 1969 - cited in Harremoës, 1975.)

Figure 16.2 Spectral distribution of direct solar radiation at sea level and definitions of UV and visible bands (after Jerlov, 1976). 
Figure 16.3 Short-wavelength light attenuation curves for two coastal sites $(2 \mathrm{~m}$ depth) in Lyall Bay, Cook Strait, (New Zealand) compared with coastal and oceanic optical water types from Jerlov (1976). Site B is $1.4 \mathrm{~km}$ further offshore from Site A. (From Bell et al., 1992.)

Figure 16.4 Mean diurnal curves of faecal coliform $t_{90}$ values for Wellington on typical summer and winter days based on confined experiments $(0-0.7 \mathrm{~m})$ and estimated for a $5 \mathrm{~m}$ mixed layer. (From Bell et al., 1992.)

Figure 16.5 Confined results for coliform inactivation at Wellington, New Zealand during 29-31 May, 1978. (Beca Carter-Caldwell Connell, 1980.)

Figure 16.6 The relationship between $t_{90}$ and both the global solar radiation and the time of the day. (Beca Carter-Caldwell Connell, 1980.)

Figure 16.7 The correlation between $t_{90}$ and global solar radiation (Beca Carter-Caldwell Connell, 1980.)

Figure 16.8 Enterococci survival curves at different depths from a confined silica flask field experiment in Tauranga Harbour on 23 November 1990. (Adapted from Davies-Colley et al., 1993.)

Figure 17.1 A current frequency rose (after Grace, 1978).

Figure 17.2 The horizontal and vertical concentration distributions in the moving element.

Figure 17.3 The exact and approximate theory for the case where the side and lower concentration boundary layer merge at the same point.

Figure 17.4 The exact and approximate theory for the case when there is diffusion only in the horizontal (y) direction. 
Figure 17.5 Final positions of particle centres with source at site $\mathrm{J}$ (2.6 km offshore from Waitara, Figure 15.8) for a persistence period of 24 hours (from Bell, 1987).

Figure 17.6 The visitation frequencies of effluent particles reaching the shoreline in segment 2 (Figure 15.8) for a range of plume ages up to 12 hours (Bell, 1987).

Figure 17.7 The cumulative frequency distribution of faecal coliform concentrations arriving at segment 2 (Figure 15.8) for particular hours of the day (Bell, 1987).

Figure 17.8 Examples of a nested finite difference grid for the Wellington/Lower Hutt outfall study (Bell et al., 1992) and a near orthogonal curvilinear grid for the Manukau Harbour outfall study (van der Kuur et al., 1989).

Figure 17.9 Example of a triangular finite element grid generated by TRIGRID. Triangle size is related directly to water depth to yield similar Courant numbers [courtesy R.F. Henry, (IOS - Canada)].

- Figure 17.10 Schematic outline of advective and diffusive vector components of a two-dimensional horizontal random walk model.

Figure 17.11 Observed and predicted tracer concentrations during and after a continuous 11-hour release starting at 07.15 and terminating at 18.45 on 27 October (Munro 1991).

Figure 18.1 Schematic view of the Malabar ocean outfall.

Figure 18.2 Riser pressure distributions prior to purging.

Figure 18.3 Modes of seawater intrusion into high riser outfalls.

Figure 18.4 A scenario for development of circulation blocking in a high riser outfall. 
Figure 18.5 Definition sketch of circulation blocked outfall.

Figure 18.6 Ratio of circulating seawater flow to sewage flow expressed as a function of ratio of flow to critical flow rate required for purging.

Figure 18.7 Critical Froude number as a function of the friction parameter.

Figure 18.8 Flow of effluent in an outfall tunnel.

Figure 18.9 Form of the effluent layer as measured in laboratory experiments for effluent flows which are less than $\left(\mathrm{Q} / \mathrm{Q}_{\mathrm{TC}}=0.71\right)$ and greater than $\left(\mathrm{Q} / \mathrm{Q}_{\mathrm{TC}}=1.04\right)$ the purging flow.

Figure 18.10 Flooding of a tunnelled outfall following shut-down of effluent inflow.

Figure 18.11 Flow of an effluent layer along the tunnel at commissioning of an outfall.

Figure 18.12 Calibration of the Malabar systems model to the calculated rating curve for the prototype.

Figure 18.13 The gas burner type diffuser.

Figure 18.14 Venturi as a means of limiting seawater intrusion.

Figure 19.1 The Hastings Outfall (sample sites).

Figure 19.2 Annual mean most probable number of presumptive faecal coliforms/100 me at Haumoana Beach near the Hastings outfall.

Figure 19.3 The position of the Sydney outfall and the deep water control and sampling sites. 
Figure 19.4 The occurrence of faecal coliform at Sydney beaches prior to the outfall commissioning $(1,2$ and 3 are the Manly Beaches and 4 is the Malabar Beach) (Philip 1991).

Figure 19.5 The occurrence of faecal coliform at Maroubra Beach prior to and after the commissioning of the Sydney outfalls (Philip 1991).

Figure 19.6 Discharge at headworks and salinity in risers for Eastbourne Outfall. Riser 2 is the most seaward riser.

Figure 20.1 The pressure forces on a cylinder at a range of distances from a solid boundary.

Figure 20.2 A wave height record over 2.5 minutes at Tatapouri, New Zealand.

Figure 20.3 Waves over a pipe line (Nomenclature).

Figure 20.4 The movement of vortices behind a cylinder in a wave field for a range of values of Keulegan Carpenter numbers $\left(K_{c}=U_{\max } T / d\right)$. The cylinder is remote from any boundary. (From Sarpkaya and Isaacson 1981.)

Figure 20.5 The values of the horizontal and vertical forces $\left(\mathrm{F}_{\mathrm{H}}\right.$ and $\left.F_{v}\right)$ as waves pass over a pipe for $K_{c}\left(U_{\max } T / d\right)$. In the $F_{v}$ component note the higher harmonic at the larger $\mathrm{K}_{\mathrm{r}}$. (From Wright 1979.)

Figure 20.6 The wave force coefficients (after Det Norske Veratas 1981).

Figure 20.7 The trestle used for the construction of the Timaru Outfall.

Figure 20.8 (a) The pipe in position and (b) being lowered from the trestle. (Note the anode protection system). 
Figure 20.9 Pipe launching using the bottom pull method.

Figure 20.10 The pulling load in the bottom pull method Cape Peron Outfall (Cox and Kersall 1986).

Figure 20.11 Pipe launching using the float and lower method.

Figure 20.12 The sea horse used at the Marsden Point Power Station outfall (courtesy of J Lumsden).

Figure A4.1 The nomenclature for the case of a flow making an arbitrary angle to the ambient flow direction.

Figure A4.2 A comparison of the computed and measured trajectories for a buoyant fluid ejected in a horizontal plane perpendicular to an ambient flow. The data of Chu $(1974,1975,1985)$.

Figure A4.3 A comparison of the computed and measured trajectories for a buoyant fluid ejected in a horizontal plane perpendicular to an ambient flow. The data of Ayoub (1971).

Figure A4.4 A comparison of the computed and measured trajectories for a buoyant fluid ejected in a horizontal plane perpendicular to an ambient flow. The data of Ayoub (1971).

Figure A4.5 A comparison of the computed and measured trajectories for a buoyant fluid ejected in a horizontal plane perpendicular to an ambient flow. The data of Ayoub (1971). 